\title{
Brazil: taming inflation expectations ${ }^{1}$
}

\author{
Afonso S Bevilaqua ${ }^{2}$, Mário Mesquita ${ }^{3}$ and André Minella ${ }^{4}$
}

\section{Introduction and background}

Brazil adopted inflation targeting (IT) in the aftermath of the devaluation and floating of the real in $1999 .{ }^{5}$ The new regime was instrumental to anchor expectations after the collapse of the nominal exchange rate peg, and marked a substantial improvement regarding the transparency of monetary policymaking in Brazil. Initial concerns about fiscal dominance proved unfounded, as fiscal policy was strengthened in line with the requirements of the new regime. Instead, the early years of IT in Brazil were marked by three waves of currency depreciation, to which monetary policy reacted. ${ }^{6}$ The Brazilian real (BRL) weakened by $48.9 \%$ in 1999 , by $18.5 \%$ in 2001 and by $53.2 \%$ in 2002 . While there were signs, and consensus amongst analysts, that the real had been substantially appreciated before the float, the exchange rate moved progressively towards equilibrium in the following couple of years, so that the potential inflationary impact of additional depreciation, and the actual fallout, became gradually more severe. For 2001, for instance, the Central Bank of Brazil (BCB) estimated that inflation would have been $4.8 \%$ in the absence of exchange rate depreciation, not too far from the $4 \%$ target, as opposed to the $7.7 \%$ actual rate (Figure 1 ).

Since the beginning of the IT regime, inflation expectations have played an important role in the policymaking process. Regular surveys of market expectations on inflation, taken amongst some 100 professional forecasters, mainly financial institutions, have been compiled since the early years of the regime and a summary of consensus macroeconomic forecasts is published weekly. ${ }^{7}$ In order to strengthen incentives for accurate reporting of forecasts, the BCB regularly publishes rankings of the best short- and medium-term forecasters of several variables. The survey system in place has been considered exemplary and has been imitated by other central banks.

Simply put, the BCB's monetary policy committee (Copom) guides its policy decisions by its own forecasts for inflation in the relevant time horizon and the prospective balance of risks. Market expectations of inflation are important inputs in the BCB's forecasting models, as is usual in this framework. Expectations, in turn, have been influenced by past inflation

1 We thank Carlos Hamilton V Araújo, Rodrigo Azevedo, Eduardo J A Lima, Eduardo Loyo and Alexandre Schwartsman for comments. The views expressed in the paper are those of the authors and do not necessarily reflect those of the Banco Central do Brasil (BCB).

2 Deputy Governor for Economic Policy, Banco Central do Brasil. E-mail address: afonso.bevilaqua@bcb.gov.br.

3 Deputy Governor for Special Studies, Banco Central do Brasil. E-mail address: mario.mesquita@bcb.gov.br.

4 Research Department, Banco Central do Brasil. E-mail address: andre.minella@bcb.gov.br.

5 The first two sections draw heavily on Bevilaqua and Loyo (2005).

6 Bevilaqua and Azevedo (2005) describe foreign exchange developments during this period.

7 In addition to forecasts of various inflation indices (annual and monthly), the weekly publication includes annual forecasts of interest rates, exchange rates, the trade and current account balances, FDI, GDP growth, industrial production, and net public sector debt. The BCB's website (www.bcb.gov.br) contains daily data on median, average, and standard deviation of inflation forecasts, starting, for the official inflation index, in January 2000. A fledgling market for long-dated inflation-linked government bonds in principle creates scope for derivation of inflation expectations from asset prices. However, relatively low liquidity at time horizons that are policy relevant has so far limited the reliability of these indicators. 
behavior, the inflation targets, exchange rate and commodity price developments, economic activity, and the stance of monetary policy. Recursive estimates suggest that the backwardlooking component of market expectations has been ceding ground to the inflation target, evidence that the IT system is gaining credibility. Nevertheless, as will be seen below, credibility has not been perfect, so oftentimes inflation expectations seem to have over-reacted to current developments, in particular to upward inflation surprises. Thus, the BCB often had to act so as to prevent negative short-term developments from contaminating the medium-term outlook. In this sense, the process of disinflation has been, and still is, a process of taming inflation expectations.

\section{3: disinflation and recovery}

The 2002 sudden stop of capital inflows and consequent currency depreciation left a burdensome legacy for monetary policy. The BCB's challenge was to undertake major disinflation in an environment of limited credibility ("conservative" monetary policy having been a constant focus of heavy criticism by the political party that won the elections of that year), and after inflation expectations had shifted upwards in an apparently persistent fashion. The monetary policy response began before the political changeover was completed, in an off-schedule meeting of the monetary policy committee on October 14, 2002 , when the basic interest rate was hiked by 300 basis points to $21 \%$ pa. This was the first and last, to date, Copom meeting outside the pre-announced schedule since the beginning of the IT regime. Monetary tightening continued until February 2003, with a cumulative 550 basis point increase in the basic interest rate, which peaked at $26.5 \%$ pa, complemented by an increase in the reserve requirements of commercial banks.

Given Brazil's history of chronically high inflation, which both thrived on and fostered sophisticated indexation techniques, monetary policymakers naturally had a stronger preference against too gradual a disinflation process, even if that might have been desirable from the viewpoint of minimizing GDP volatility - and even this last point is questionable. ${ }^{8}$ Issues of credibility also argued for faster rather than more protracted disinflation. First, despite the new government's commitment to fiscal austerity, confirmed by the increase in the target for the primary (before interest spending/revenues) surplus of the consolidated public sector from $3.75 \%$ of GDP in 2002 to $4.25 \%$ in 2003 , there was still concern about fiscal dominance. The argument was that monetary tightening would worsen debt dynamics, thereby leading to BRL depreciation and higher, rather than lower, inflation. ${ }^{9}$ Another line of reasoning, which is still recurrent in Brazil, despite the results of recent years, refers to monetary policy ineffectiveness, presumably derived from blockages in the transmission mechanism (low credit-to-GDP ratios and limited if not perverse wealth effects owing to a large share of floating rate public debt) and the presence of indexation of utility rates and other contracts.

Thus a strategy of relatively rapid disinflation was adopted and implemented, in spite of difficult initial conditions. The average monthly inflation rate between October 2002 and March 2003 was $1.9 \%$, or some $25.5 \%$ in annualized terms, and inflation expectations for 2003 continued to worsen until late April, peaking at 12.5\%, compared with an (adjusted) inflation target of $8.5 \%$, with expectations for 2004 at $8.0 \%$. It was only when Copom decided, in its April 2003 meeting, against tremendous public outcry, to keep the basic Selic rate unchanged at $26.5 \%$ pa for the third month in a row, that monetary resolve showed

\footnotetext{
Ball (1994).

9 Blanchard (2005).
} 
signs of paying off by lowering expectations. These started subsiding for both the 2003 and 2004 horizons. ${ }^{10}$ The Selic went unchanged again in May, and by the June policy meeting market expectations for 2003 and 2004 had receded to $11.7 \%$ and $7.4 \%$ respectively. Copom opted for a modest 50 basis point rate cut in June. When the committee met in July, expectations had fallen to $10.4 \%$ for 2003 and $6.5 \%$ for 2004 , which prompted a further $150 \mathrm{bp}$ rate cut, bringing the Selic to $24.5 \%$ pa.

A powerful signal that the government supported the disinflation strategy was given in late June, when it set a 5.5\% official inflation target for 2004 (remember that inflation was $12.5 \%$ at the end of 2002) and a $4.5 \%$ target for 2005 , both with a tolerance margin of $\pm 2.5 \%$. The fruits of assertive monetary policy became apparent by mid-year, when monthly inflation, helped by appreciation of the BRL, was very low (there was actually deflation in June) (Figure 2). As would recur in the following years, this quickly elicited claims that inflation was dead in Brazil, and that the way was already open for even faster monetary easing. Copom's interpretation of events was that the mid-year collapse of inflation was a transitory event. The committee took comfort instead in the fact that, indeed, estimates of inflation persistence were on the way down, auguring well for further disinflation.

At that stage the challenge was to calibrate the pace of monetary easing so as not to put the disinflation process at risk. BCB officials signaled, through statements and Copom minutes, that rate cuts would continue as long as disinflation progressed but that the reduction would follow a gradual approach. A special effort was made to spread the familiar message that monetary policy affects the economy through shifts in the entire term structure of interest rates, which in turn depends on the overnight rate as well as on where markets think overnight rates will be in the future. In a process of disinflation, the current Selic rate was, by itself, a particularly poor measure of the policy stance, as market rates for longer maturities, which are the ones relevant for the pricing of bank credit, already incorporated expected rate cuts. Too steep a (negatively sloped) yield curve could undermine the intended contractionary stance, and therefore jeopardize the disinflation path.

With actual twelve-month accumulated inflation averaging $3 \%$ pa between June and November 2003, inflation expectations fell sharply, creating scope for significant easing. From the beginning of the easing cycle to November 2003, the nominal Selic was cut by $900 \mathrm{bp}$, and the one-year nominal rate fell by $820 \mathrm{bp}$, while the inflation-adjusted one-year rate fell by almost $500 \mathrm{bp}$. There was, thus, substantial monetary stimulus already in the pipeline.

Towards the end of the year inflation expectations for 2004 were close to $6 \%$ pa, compared with a target of $5.5 \%$ for the year and with $8 \%$ expected in the beginning of the year. Expectations for 2005 were at 5\%, higher than the 4.5\% target, but also lower than they had been at the beginning of the year. Under these circumstances, another rate cut of $100 \mathrm{bp}$ was undertaken. By that time it was apparent that the economy had recovered fairly rapidly from its early 2003 slowdown. In fact, after contracting in 2003Q2 and growing by just 2\% in annualized terms in 2003Q3, growth surged to about $7 \%$ in the last quarter of the year.

\section{4: inflation rebound and policy response}

Inflation had accelerated in late 2003 and early 2004, activity was strengthening at a healthy clip, and a substantial share of previous monetary impulses was yet to feed through the

10 Targets are set by the National Monetary Council (CMN) in June for the inflation of the calendar year, two years ahead. However, in January 2003, the BCB announced that it would follow an adjusted target of $8.5 \%$ for 2003 and of $5.5 \%$ for 2004. 
economy. In that environment, after a pause in the January meeting, Copom cut rates again in March and April, now by a more parsimonious total of $50 \mathrm{bp}$. During the early months of 2004 , rising prices of manufactured goods at the wholesale level posed a short-term risk for consumer price inflation. However, expectations for consumer price inflation remained stable throughout March and early April, which suggested that current inflationary pressures would not have a lasting impact.

The outlook for inflation worsened substantially thereafter, under various negative influences. The most visible, albeit not the sole, trigger for this process was a sudden, sharp, depreciation of the real ahead of the beginning of the cycle of monetary tightening in the US. The sovereign spread widened from $559 \mathrm{bp}$ at the end of March to $650 \mathrm{bp}$ at the end of June, and the exchange rate, which had been relatively range-bound around BRL2.90/USD since the beginning of February, rose to BRL3.20/USD within a few weeks. Interestingly, these movements were soon reversed, as the country's improved balance of payments position reasserted its influence over asset prices. Nevertheless, the damage on the inflation front was more lasting, and would eventually elicit a policy response.

Inflation expectations for 2004 had been stable, a little over $6.0 \%$, compared with a target of 5.5\%. Similarly, expectations for 2005 were stable at 5.0\%. Revisions to forecasts in the first fourth months of the year mostly reflected short-term inflation surprises and had not impacted the public's medium-term inflation scenarios. This changed in May, when depreciation of the real, in an environment of strong economic activity, led to increased projections for changes in wholesale prices and in so-called managed prices. ${ }^{11}$ Inflation expectations for the coming twelve months increased from $5.5 \%$ at the time of the April policy meeting to $5.7 \%$ in the May meeting, and to $6.0 \%$ at the time of the June meeting, months in which the basic rate was unchanged. Heightened uncertainty regarding the external scenario, thanks to the looming Fed tightening, translated into increased uncertainty about the domestic inflation outlook, impacting the targets' role as an attractor to market expectations. The influence of current and expected BRL depreciation over the inflation outlook called for additional policy caution. In sum, not only was there an upward shift in the path of expected inflation, but uncertainty surrounding this path was also increasing. ${ }^{12}$

It is worth stressing that currency depreciation was not the only issue, as other factors were also important drivers of the process. As of mid-2004 the economy was growing by about $5 \% \mathrm{pa}$, after two quarters expanding by close to $7 \% \mathrm{pa}$, signaling that the output gap was probably closing. Moreover, indices of capacity utilization in manufacturing were above historical averages, in some sectors actually reaching unprecedented levels. Clearly, these signs suggested that currency depreciation and rising commodity prices hit an economy where firms faced favorable conditions to increase their prices.

At the end of June the National Monetary Council (CMN) set the inflation target for 2006 at $4.5 \%$, and narrowed the tolerance interval to $\pm 2 \%$. By that time, the prospects for further easing had dimmed, and market participants began to ponder, and price in, the eventuality that a new cycle of tightening might be needed to ensure convergence of inflation to the targets (Figure 2). Inflation expectations continued to increase, from $6.1 \%$ as of the July

11 About a third of the official inflation index, the IPCA, consists of prices that are set by contracts rather than by the interplay between current demand and supply. These prices are dubbed "managed". Said contracts often include backward indexation clauses, linking the change in managed prices to the accumulated changes in the IGP-DI family of inflation indices, in which wholesale prices dominate, and which are themselves highly sensitive to exchange rate changes, as they have an important commodity component. Thus, real depreciation and/or increases in international prices of export commodities tend to have a meaningful lagged impact on managed prices.

12 The standard deviation of twelve-month ahead inflation expectations, for instance, rose from a $0.43 \mathrm{pp}$ average in April to a 0.76 pp peak around the September meeting. 
Copom meeting to $6.2 \%$ in August, with the basic rate still unchanged. Continuously deteriorating market expectations indicated that inflation, without policy intervention, would not slow down on its own, and would not converge towards the targets.

Thus, in September the basic rate was increased to $16.25 \%$ pa, the beginning of the first cycle of monetary tightening under the inflation targeting regime that was not a consequence of financial distress (after peaking at around $700 \mathrm{bp}$ at the end of May, the sovereign spread was below 500 bp by September; similarly, the real had strengthened from BRL3.19/USD to BRL2.86/USD).

Clearly, given the lags in the transmission mechanism of monetary policy, it was important, at the time, to signal to the public what would be the strategy to bring about convergence towards the $4.5 \%$ targets for $2005-06$, as it was clear that inflation was going to deviate substantially from the targeted path in 2004. Therefore, in the September meeting minutes Copom outlined a gradualist approach to deal with the consequences of the expected overshoot of inflation in 2004. The committee estimated that regular inflationary inertia stemming from the expected 2004 overshoot would amount to $0.9 \%$ in 2005 . Making use of the flexibility inherent in the inflation targeting regime and in a manner consistent with maximum transparency, the committee opted to accommodate $2 / 3$ of this inertia, namely adopting an explicit policy objective of $5.1 \%$ inflation in 2005 , rather than the $4.5 \%$ target midpoint. This was tantamount to extending the length of the convergence period from 12 to 24 months, as the target for 2006 remained unaltered.

More important, by committing to a $5.1 \%$ objective for 2005 , Copom indicated that it would not allow inflation to remain close to the top end of the acceptable range, the $7 \%$ neighborhood to which market expectations seemed to be converging. Besides laying out clearly its baseline disinflation objectives, Copom announced that it would respond asymmetrically to shocks that could disturb the baseline trajectory, remaining particularly vigilant against the effects of shocks that threatened to increase the deviation of inflation from the original targets, while taking full advantage of favorable shocks that might help bring inflation down towards those targets.

Monetary tightening had limited initial impact on inflation and inflation expectations. In the last three months of 2004 , annualized core inflation was running at around $7.5 \% \mathrm{pa}$, and rising. Inflation expectations for 2005 were hovering at $5.8 \%$, higher than before the beginning of the cycle, despite various factors that might have helped, such as a tighter policy stance, currency appreciation, signs of accommodation in economic activity and lower international prices of some important commodities. Market participants and professional forecasters were clearly skeptical about the prospects for disinflation.

This skepticism had several causes, in addition to the inevitable credibility issues in a regime that had faced so much turbulence in its early years and in which institutions were still evolving. As the balance of payments continued to improve and asset prices to rise, the link between the basic interest rate and market rates appeared to have become weaker than in previous cycles, in a Brazilian version of the yield curve "conundrum". Three months after the 2001 tightening cycle had begun, for instance, the spread between the one-year rate and the basic rate stood at $540 \mathrm{bp}$, and the ex-ante real one-year interest rate had increased by $630 \mathrm{bp} .{ }^{13}$ This time, after three additional basic rate hikes, the yield curve had flattened, and the increase in the one-year real interest rate was just $40 \mathrm{bp}$. Moreover, buoyant asset prices contributed to preserve private sector wealth as well as consumer confidence, which may have further hindered the transmission of the monetary tightening.

13 The spread was also very wide, some $360 \mathrm{bp}$, at a similar point in the 2002-03 tightening cycle. 
Last, but not least, institutional changes adopted in 2003 began to take effect, fostering credit growth, especially to the household sector, thereby supporting the demand for consumer durables. ${ }^{14}$ New lending to households increased by $9 \%$ between the third and fourth quarters of 2004, against an increase of $6 \%$ in the same period of 2003 , and year-on-year growth in the stock of credit to households reached 37.8\% in December 2004, compared with $29.3 \%$ in September.

As of the December policy meeting, when the Selic was increased by 50 bp to $17.75 \%$ pa, there were as yet no clear signs of convergence to the inflation target path.

\section{5-06: consolidating disinflation}

The first quarter of 2005 finally brought some relief on the inflation front, with longer horizon projections by the BCB as well as independent analysts pointing to slower price increases. However, annualized core inflation was still at some $7.8 \%$, far from the target path. Despite improvements in the medium-term outlook, market participants were still revising upwards their inflation expectations for 2005, from 5.7\% in December 2004 to 5.9\% in March, away from the policy objective. In this scenario the basic interest rate increased by an additional $150 \mathrm{bp}$, in three monthly installments of $50 \mathrm{bp}$, during the first quarter.

By the second quarter of 2005 monetary policy was at a crossroads. Forward looking analysis and model projections of inflation by $\mathrm{BCB}$ economists were pointing towards convergence to the target sometime in 2006, but current rates of inflation remained stubbornly high. Moreover, under the influence of negative current inflation data, inflation expectations of independent analysts were still diverging from the targets. Specifically, inflation expectations for the twelve months through December 2005 were moving towards $6.5 \%$, compared with the policy objective of $5.1 \%$ and the original target of $4.5 \%$ for the year (Figure 3). Thus, in April and May the basic rate increased by 50 bp more. These not entirely anticipated policy moves strengthened the perception, amongst market participants, that Copom would not allow inflation to become entrenched above the targeted path.

During the disinflation process, when central bank credibility is still being established, inflation expectations tend to over-react to current developments. This reinforces the case for a commitment by policymakers to allow positive surprises to be fully incorporated into firms' price setting decisions, while actively counteracting negative surprises. The authorities' avowedly asymmetric stance meant that a series of favorable inflation surprises, in June, July, and August, led to a sharp fall in the mean and dispersion of inflation expectations, as convergence toward the target accelerated (Figure 4). It is not that the last couple of $25 \mathrm{bp}$ rate hikes broke inflation inertia, but rather the cumulative effect of previous policy moves combined with the signaling effect of these last few increases seem to have done the trick.

Currency appreciation, on the back of strong balance of payments fundamentals, contributed importantly to the process, as part of the transmission mechanism in an open economy, with tradable goods prices leading the disinflation process. Although tradable goods initially led the way towards the inflation targets, the stance of monetary policy helped to spread the disinflation process to the prices of nontradables, including services. ${ }^{15}$

With rates unchanged until September, the disinflation process was consolidated during the middle of 2005, when the economy was cooling off. In fact, GDP growth would fall from an average of $3.2 \%$ in the first half of the year to $0 \%$ in the second half. The argument for

14 Expansion of payroll backed loans, regulated by a 2003 law, was, and remains, particularly strong.

15 See the box "Preços de Itens não Comercializáveis - Evolução Recente" in Banco Central do Brasil (2006). 
persistence with a firm monetary policy stance, even in the face of a temporary deceleration of growth, stressed the fact that the BCB was already pursuing an objective that exceeded the target set by the National Monetary Council, and that, while moving towards the targeted path, inflation expectations, and inflation itself, were even higher than the $5.1 \%$ objective (inflation ended at $5.7 \%$ for the year as a whole). Moreover, there was in that period no major supply shock that would justify reconsidering the announced strategy and allowing inflation to drift towards the upper limit of the $\pm 2.5 \%$ band. The authorities' stance, in sum, tried to ensure that the Brazilian inflation targeting regime began to see inflation hovering around the central target, instead of permanently moving between the central target and the ceiling of the acceptable range. Short-term costs, in terms of foregone economic activity, should be seen as an investment in stability, one that would pay off in the years to come through increased monetary policy credibility and effectiveness, and a reduction in the inflation risk premium would lead to lower real interest rates in the medium term, and hence faster growth.

By September 2005 inflation expectations for 2006 were down to 4.6\% (Figure 3), close to the $4.5 \%$ target, and a new process of monetary easing could begin with a 25 bp rate cut. This was followed by additional cuts of $150 \mathrm{bp}$ in the last three policy meetings of the year. In October 2005 Copom announced that, thanks to the economy's reduced vulnerability to shocks, it would lower the frequency of its meetings from twelve to eight per year - every 45 days or so - starting in January 2006. The easing cycle that began in the third quarter of 2005 , and which continues to this day, has been the first sustained monetary relaxation process under the IT regime that did not coincide with the recovery period after a financial crisis, and as a result saw smaller initial changes in asset prices. In spite of the apparent effects of monetary policy shifts on the relevant macroeconomic variables, the old theme of ineffectiveness emerged again during the course of the ongoing cycle.

Because the previous easing cycle (2003-04) had been largely anticipated by the markets, the yield curve became inverted in the second quarter of 2003 , leading to a fall in the cost of credit, which drove a recovery from the third quarter of that year. The same type of anticipation happened in 2005. Longer rates (specifically the 360-day swap rate) began to fall by April 2005, five months before the actual beginning of the easing process, and, as seen above, at about the same time as inflation started to turn around. Understandably, however, this effect was more muted than in 2003 , when the basic rates had been raised much higher: when the 2003 loosening cycle began, the spread between the long rate and the basic rate was $-330 \mathrm{bp}$; in the beginning of the current cycle this spread was $-159 \mathrm{bp}$. In both episodes, the yield curve would gradually become less inverted, but this flattening move started earlier in the 2003-04 cycle.

Thus, neither was the qualitative behavior of the yield curve in 2005 a novelty, nor was the fact that longer rates started falling ahead of the basic policy rate and that their fall slowed down while the basic rate kept being reduced proof of any decline in policy effectiveness. On the contrary, longer rates seem to have become, if anything, more sensitive to actual and expected changes in the basic interest rate. This, in turn, is consistent with the hypothesis that monetary policy has gained credibility and works through smoother movements in the basic rate, and also with a scenario in which, with lower macroeconomic vulnerability to shocks, risk premia are smaller and less volatile.

Copom continued to cut the basic interest rate aggressively throughout the earlier part of 2006, bringing it back to $15.25 \%$ pa in May, until then the minimum under the IT regime. At that meeting the committee reduced the pace of easing, from $75 \mathrm{bp}$ to $50 \mathrm{bp}$. The move had been signaled in the minutes of previous policy meetings, and was anticipated. Yet, the decision came during a period of stress in international financial markets that led to a spike in local market rates, so some market participants actually positioned themselves for a cut of just $25 \mathrm{bp}$ or even a pause in the process. Yet the economy had, basically through substantial external deleveraging, become more resilient to mood swings in international markets, and asset prices soon recovered as it became clear that the changing international scenario would not jeopardize access to the necessary external funding. 
Rather than the external scenario, at that stage the main risks to an otherwise benign inflation outlook referred to the transmission mechanism of monetary policy and the behavior of commodity prices, especially oil. Given the relatively short time series, estimates of the lags of the transmission mechanism are inevitably less robust for Brazil than for economies with a longer history under the monetary policy regime in force. Moreover, recent innovations in the credit market have the potential to impinge on the transmission mechanism. In addition, the easing process has lasted for more than a year, and has brought nominal and inflation-adjusted interest rates to historical lows. If the traditional pattern holds, however, the current state of domestic demand in Brazil does not yet incorporate fully the effects of the monetary easing already observed.

International oil prices continued to increase until late August, but have receded since then. Despite this latest move, oil prices are still highly volatile, and a new upward trend cannot be ruled out. While Brazil's self-sufficiency in oil shields the current account from oil prices, rising fuel costs could have an important effect on inflation, not only through their direct impact on the official consumer price index (IPCA), but also through likely increases in managed prices such as bus fares and other potential second round effects. Moreover, higher oil prices feed through the important petrochemical production chain, and tend to have a non-negligible impact on inflation expectations.

Inflation expectations continued to drift lower throughout 2006. Median market forecasts for inflation in 2006 broke through the 4.5\% target by early April, and those for 2007 broke through the target some five months later. Specifically, at the time of writing market expectations for 2007 were around $4.1 \%$, compared with a target of $4.5 \% \pm 2 \%$. Copom continued to cut the basic interest rate throughout the second half of 2006, for a total of $200 \mathrm{bp}$ in four meetings, bringing it to $13.25 \%$ pa in November, its lowest level ever. Last year, for the first time since the adoption of the IT regime, inflation undershot the target midpoint, but remained within the tolerance band, closing the year at 3.1\%. This was a novel experience for Brazil, although quite usual for other inflation targeting economies. Its importance should not be underestimated, since private agents, if they regard the lower half of the tolerance band as all but unattainable, would hardly choose to assign to inflation a subjective probability distribution with a mean at the target midpoint. For as long as expectations remain biased towards the upper half of the tolerance band, the monetary authority has to keep actively leaning against such skepticism just to hit the midpoint.

\section{Inflation expectations: convergence to the targets and lower inflation uncertainty}

The critical test of implementation of IT is whether policy is able to anchor expectations to the targets. In the early years of the regime, the economy underwent several shocks, as discussed above, and consequently, in some periods the BCB pursued either adjusted targets, such as the one announced in January 2003, or an off-center objective within the original target range, announced in September 2004, which constituted the focal point for agents. In the early stages of the inflation targeting regime, expectations converged to the declining targets, but during the confidence crisis in 2002 they deviated substantially from the target path (Figure 5). Recently, however, they have been put back on track.

There is evidence that monetary policy under IT and the overall improvement in macroeconomic fundamentals in Brazil have contributed substantially to create a more stable and predictable environment. In particular, there are signs that inflation uncertainty has declined. One such signal is the behavior of forecast errors, measured as the difference between twelve-month actual and expected inflation (Figure 6). Since the forecast horizons overlap over time, those errors are highly correlated. Rising inflation in 2001 , and even more so in the second half of 2002 and first quarter of 2003, yielded forecast errors as high as 
$12.8 \mathrm{pp}$. However, as price acceleration was reversed, forecast errors declined. Most importantly, forecast errors became negative from November 2003 through June 2004; that is, inflation expectations formed during the confidence crisis clearly overestimated future inflation. The trough of negative errors corresponds to inflation expectations at $9.0 \%$ formed in April 2003, compared with an inflation outturn of 5.9\% in March 2004. This shows both the magnitude of the task faced by policymakers in 2003 and the extent of the change that was achieved. In recent years, forecast errors have been substantially lower. From July 2005 through August 2006, all forecast errors in absolute values were lower than $1 \mathrm{pp}$.

Another indicator of inflation uncertainty is the dispersion of inflation expectations across survey respondents. Using the Survey of Professional Forecasters in the US, Giordani and Soderlind (2003) compute the aggregate inflation uncertainty as the combination of individual uncertainty (average standard deviation of individual histograms) and disagreement on the point forecast. In the case of the Brazilian survey, however, the respondents provide only point forecasts instead of probabilities for different intervals, and the only available measure of uncertainty is the disagreement among participants. In spite of this limitation, disagreement seems to capture to a large extent the degree of inflation uncertainty, as it is known to move together with individual uncertainty in the US survey (correlation of 0.6). The coefficient of variation across respondents, measured as the ratio of standard deviation to the average, soared above 0.3 between mid-2002 and mid-2003, but has generally remained below 0.1 since late 2003 (Figure 7). After peaking at $2.6 \mathrm{pp}$, the standard deviation averaged $0.4 \mathrm{pp}$ in the last two years.

Furthermore, there is evidence that the risk premium implicit in longer-term interest rates has declined. ${ }^{16}$ Lower uncertainty about future inflation and, more directly, about the future movements in interest rates tends to strengthen the transmission mechanism of monetary policy, as it increases the signal/noise ratio of policy actions.

Moreover, the role of inflation targets as attractors for inflation expectations is found to be statistically significant in econometric exercises. Initially, we simply regress inflation expectations on inflation targets in an exercise similar to those found in the literature that tests for rational expectations. Our concern here is to test whether there is a systematic deviation of inflation expectations from the target (a constant term different from zero) and whether movements in the target affect expectations (if expectations are well anchored to targets, the slope coefficient would be close to one). We found that the constant term is positive and significant at the $10 \%$ level, indicating inflation expectations higher than the target for some relevant period (Table 1, specification I). On the other hand, an estimated coefficient on the inflation target statistically different from zero and not different from one points to the important role played by targets in the expectation formation process. These results, however, have to be analyzed with caution because of the problem of omitted variables in the regression. ${ }^{17}$

To assess the behavior of these coefficients over time, we also estimate 36 -month rolling window regressions. In particular, we are interested in checking whether a sample period that does not include the 2002 confidence crisis presents considerably different results (Figures 8 and 9). For the sample period more concentrated in the confidence crisis, the point estimates for the constant are higher than four and statistically significant, whereas for the recent period these are around zero and not significant. The coefficient declines abruptly for the sample starting in 2003 because, in this case, the sample does not contain the months immediately previous to the adoption of the adjusted target, when the difference

16 See box "Conteúdo Informacional dos Spreads de Taxas de Juros" in Banco Central do Brasil (2006).

17 We cannot assert that targets are uncorrelated with omitted variables because they have been set in light of inflation history. 
between inflation expectations and the target was large, which tends to increase the value of the constant.

The behavior of the coefficient on the inflation target over time also reflects the different stages of IT implementation in Brazil. Its estimates start around one, but decline to lower than half and become statistically not significant as the sample period is more concentrated in the confidence crisis. For the recent period, however, the coefficient is significant and close to unity. Therefore, these regressions indicate the important, albeit not uniform, role played by the inflation targets, and, in particular, for the recent period, the better anchoring of expectations by the target. ${ }^{18}$

Nevertheless, targets are not the whole story, and to assess the influence of different variables on the behavior of inflation expectations, we must include other regressors. The objective here is also to test the robustness of the previous results. We include variables that, according to a basic Phillips curve analysis, should affect inflation. Specifically, the regressors are the inflation target, the output gap - measured using a HP filter applied to the industrial production series, six-month nominal exchange rate changes, and accumulated twelve-month inflation. ${ }^{19}$

We find that the constant and output gap terms are not significant, whereas the other coefficients are all significant and have the right sign (Table 1, specification II). Furthermore, the coefficient on the inflation target is not statistically different from one. The coefficient on the exchange rate change is 0.06 , which is similar to the pass-through coefficient usually found in Phillips curve estimations for Brazil using data for the same period. Past inflation also affects inflation expectations, although the point estimate is relatively low - a $1 \mathrm{pp}$ increase in the actual twelve-month inflation impacts twelve-month ahead inflation expectations by $0.20 \mathrm{pp}$

Of course, the presence of statistically significant regressors apart from the inflation target is not necessarily an indication of low credibility of the monetary authority, but rather of how rich and complex the transmission mechanism is and of the fact that even highly credible IT regimes cannot completely eliminate fluctuations of inflation, including those associated with the business cycle. The simple presence of lags in the transmission mechanism of monetary policy implies that not all inflationary pressures will be curbed completely in the short run. Note that the dependent variable is not expectations of the inflation prevailing twelve months ahead, but expectations of the twelve-month inflation twelve months ahead. It includes, therefore, the very short run. ${ }^{20}$

We also report the coefficients in a 36-month rolling window regression (Figures 10-14). Although the point estimates differ from those in the simple regression, the pattern is similar: in the sample period concentrated around the confidence crisis, the constant term is significant and the coefficient of the inflation target is low or not significant, whereas in the recent period the opposite is true (the constant is even negative, reflecting the downward trend of inflation expectations). Furthermore, we cannot reject the hypothesis that the inflation target coefficient is one.

18 The relevant role played by the targets was also found for a shorter sample size in Minella et al (2003) and Cerisola and Gelos (2005). See also Alves and Areosa (2005).

19 We use a six-month change of the exchange rate because monthly changes are too noisy. Output gap is lagged twice instead of once because industrial production data is released with a two-month lag. One shortcoming here is that we are using revised data and the HP filter was applied to the full sample series.

20 Moreover, since inflation is calculated using the price average over the month, price increases that take place after the first week of the month also appear in the index of the following month. 
Behavior of the other coefficients presents two important results. In the recent period, the coefficient on the exchange rate change is lower (even not significant), possibly indicating a reduction in the pass-through in the economy. Most importantly, the term for past inflation is around zero and not significant. Those results are also consistent with an increasing role played by the inflation target.

As a final robustness exercise, we consider an additional specification, which includes the $\mathrm{Embi}+\mathrm{Brazil}$ and the gap between the real effective exchange rate and its trend (calculated using an HP filter) instead of the change in the nominal exchange rate (Table 1, specification III). The main difference is that past inflation is not significant in this specification when considering the full sample. The results using a rolling window regression (not shown) are, on the whole, similar to those found in the previous specification. In particular, the coefficient of past inflation is significant for the period more concentrated in the confidence crisis, but it is not significant in the recent period.

\section{Summing up}

Price stability is a precondition for faster sustainable growth. Stability should contribute to creating an environment conducive to long-term funding, be it of public debt, or the private sector, including of course labor intensive industries like housing. But long-term planning requires not only that agents are comfortable about the central forecast for inflation, but also that they attach low probability to outliers. That is to say, what matters is not only the mean or median consensus forecast of inflation, but also the floor and - more relevant given Brazil's history of large upward inflation surprises - the ceiling of such forecasts.

In this regard, while much has been achieved, Brazilian monetary policy still needs to establish a firmer track record of monetary stability. An imputed ceiling of inflation expectations twelve months ahead (which we calculated simply as the sum of mean and two standard deviations of inflation forecasts) has averaged 7.2\% pa since December 2001. Most of the time, this ceiling has been within $5 \%$ pa to $10 \%$ pa, and about $15 \%$ of the time it has actually exceeded $10 \%$ pa. Only $13 \%$ of the time has the ceiling of market expectations of inflation been below $5 \%$ pa (it currently stands at some $4.6 \% \mathrm{pa}$ ). ${ }^{21}$

The Brazilian experiment with IT illustrates, perhaps more forcefully than most other cases, the importance of credibility and the consequences of the lack thereof. Credibility was negatively affected by an erroneous notion that the government would deny support to a stability-oriented, autonomously implemented, monetary policy. In addition, a widespread misunderstanding of how monetary policy works, with recurrent qualms about policy ineffectiveness, seems to have prevailed. These handicaps have increased the effort required but have not weakened the resolve of the BCB to tame inflation expectations and to deliver on inflation convergence.

21 Inflation within $5 \%$ to $10 \%$ is clearly outside what most economists, and most central banks, would normally associate with the notion of price stability. 


\section{Table 1}

\section{Estimation of inflation expectations - several specifications}

Dependent variable: 12-month ahead inflation expectations (2000:1-2006:8)

\begin{tabular}{l|c|c|c}
\hline \multirow{2}{*}{ Regressors } & \multicolumn{3}{c}{ Specifications } \\
\cline { 2 - 4 } & I & II & III \\
\hline Constant & $1.81^{\star}$ & 0.25 & 0.97 \\
Inflation target (12-month ahead) & $(1.03)$ & $(0.58)$ & $(1.00)$ \\
& $0.80^{\star \star \star}$ & $0.77^{\star \star \star}$ & $0.60^{\star \star}$ \\
Output gap (-2) & $(0.18)$ & $(0.23)$ & $(0.29)$ \\
& & 0.09 & $0.14^{\star}$ \\
12-month inflation (-1) & & $(0.11)$ & $(0.08)$ \\
& & $0.20^{\star}$ & 0.09 \\
Six-month nominal exchange rate change (-1) & & $(0.11)$ & $(0.10)$ \\
Embi + Brazil (-1) & & $0.06^{\star \star \star}$ & \\
& & $(0.01)$ & \\
Real effective exchange rate gap (-1) & & & $0.15^{\star \star \star}$ \\
& & & $(0.05)$ \\
R-squared & & & $0.08^{\star \star \star}$ \\
Adjusted R-squared & & $0.03)$ \\
\hline
\end{tabular}

Notes: Standard errors - shown in parentheses - were corrected by Newey-West heteroskedasticity and autocorrelation consistent covariance matrix estimator since estimation residuals present autocorrelation and heteroskedasticity. ${ }^{*},{ }^{*}$, and ${ }^{* *}$ indicate the coefficient is significant at the $10 \%, 5 \%$, and $1 \%$ levels, respectively. 
Figure 1

Inflation, targets and expectations (\% a.a.)

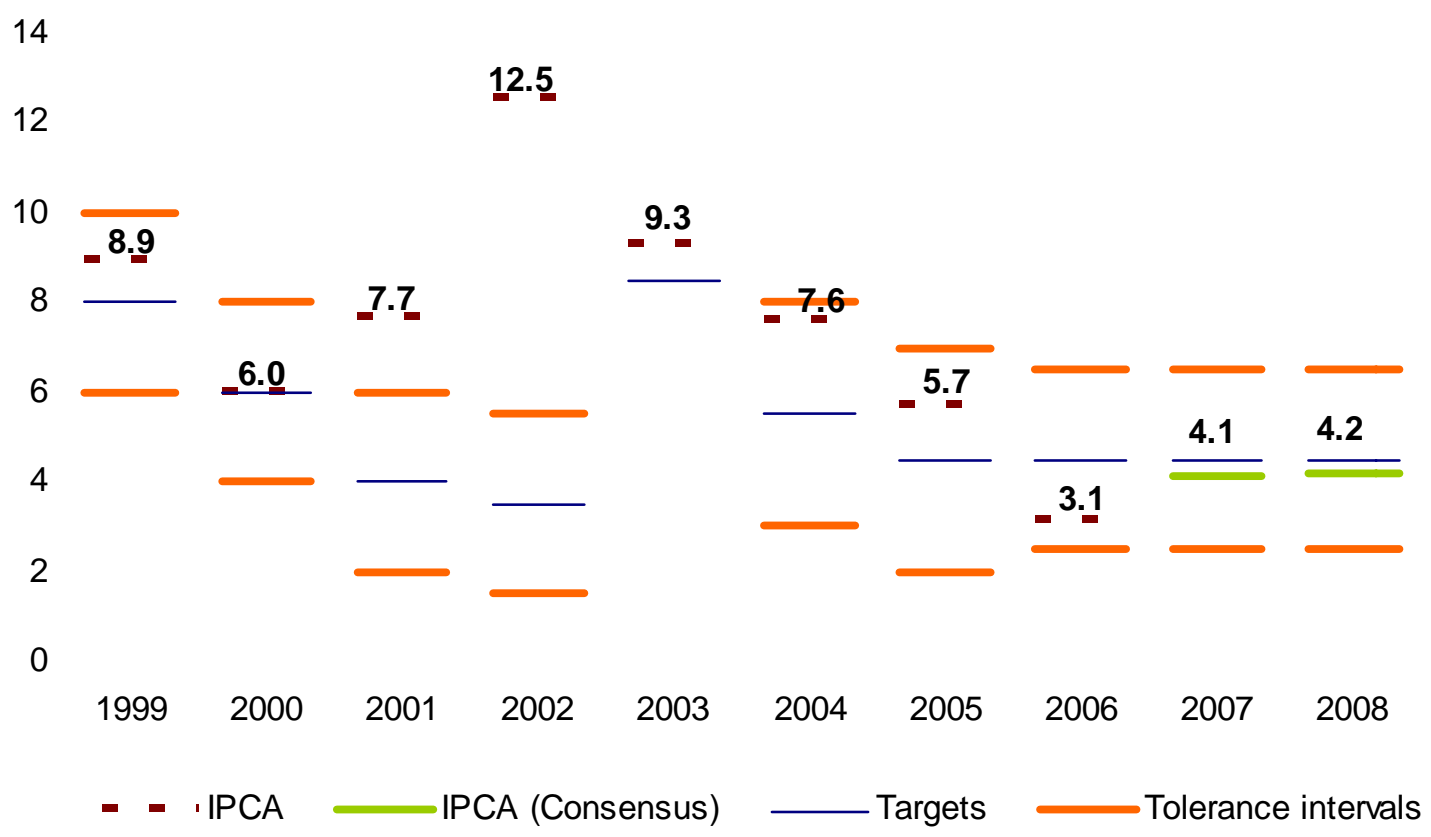

Figure 2

IPCA inflation

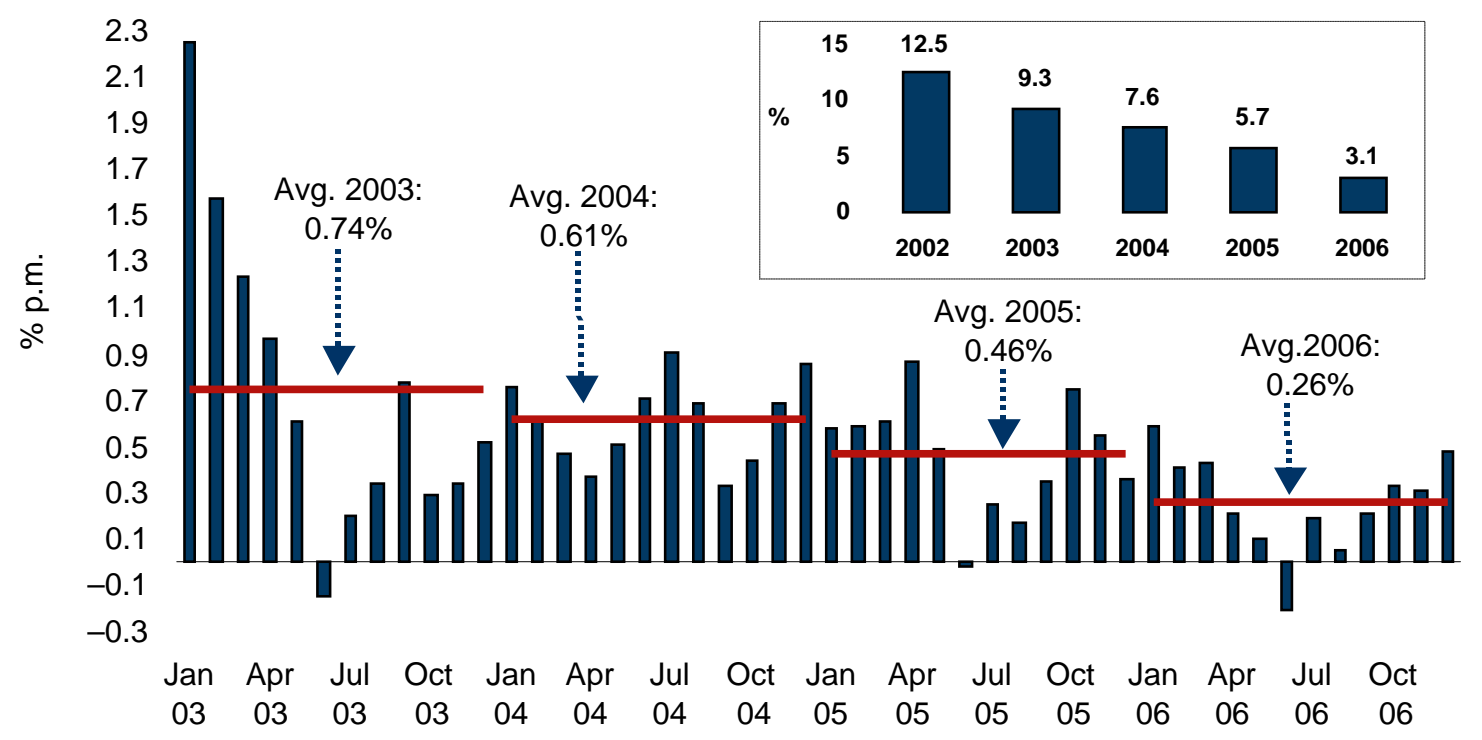


Figure 3

Market Expectations for Inflation
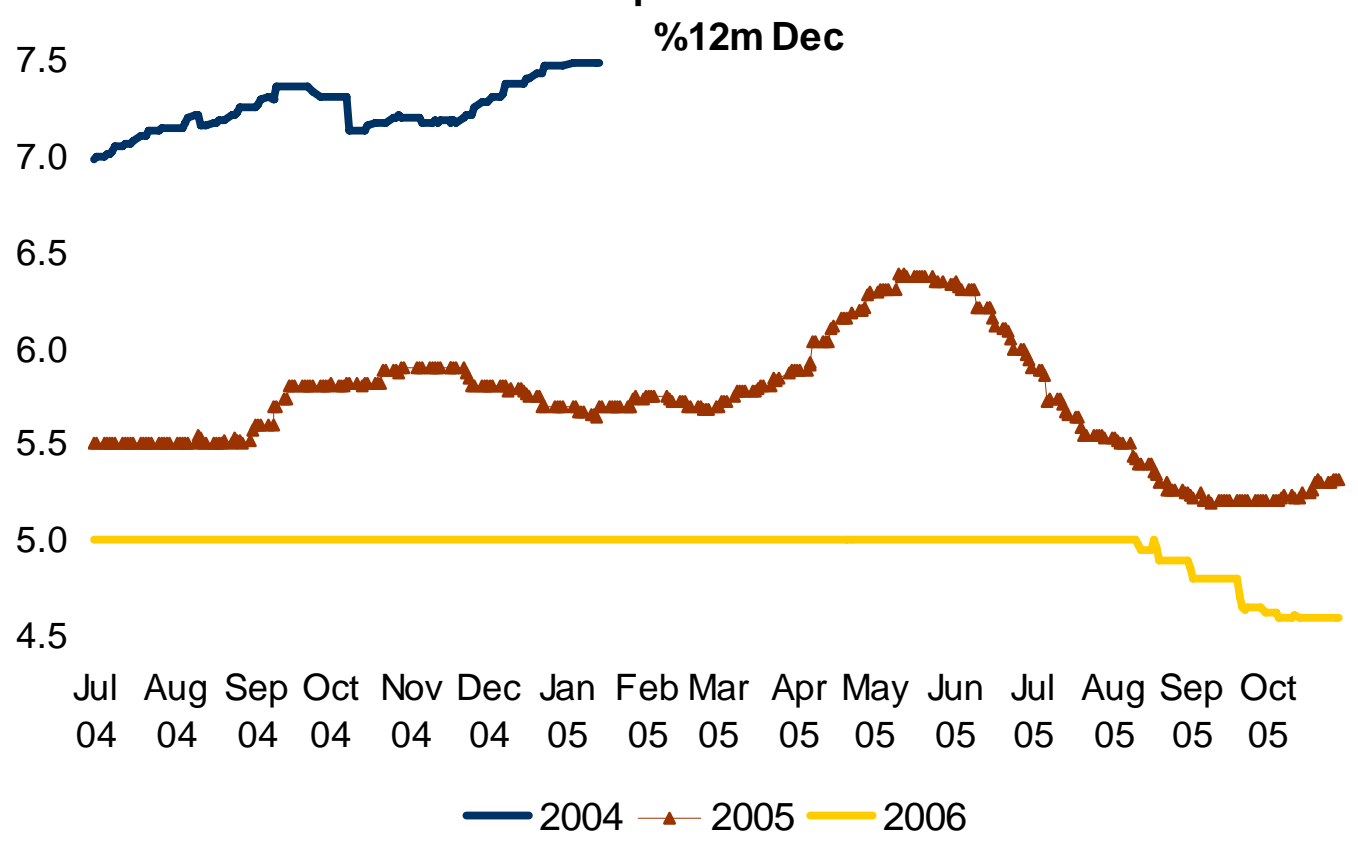

Figure 4

Market expectations for 2005 inflation in 2005

$\%$ pa

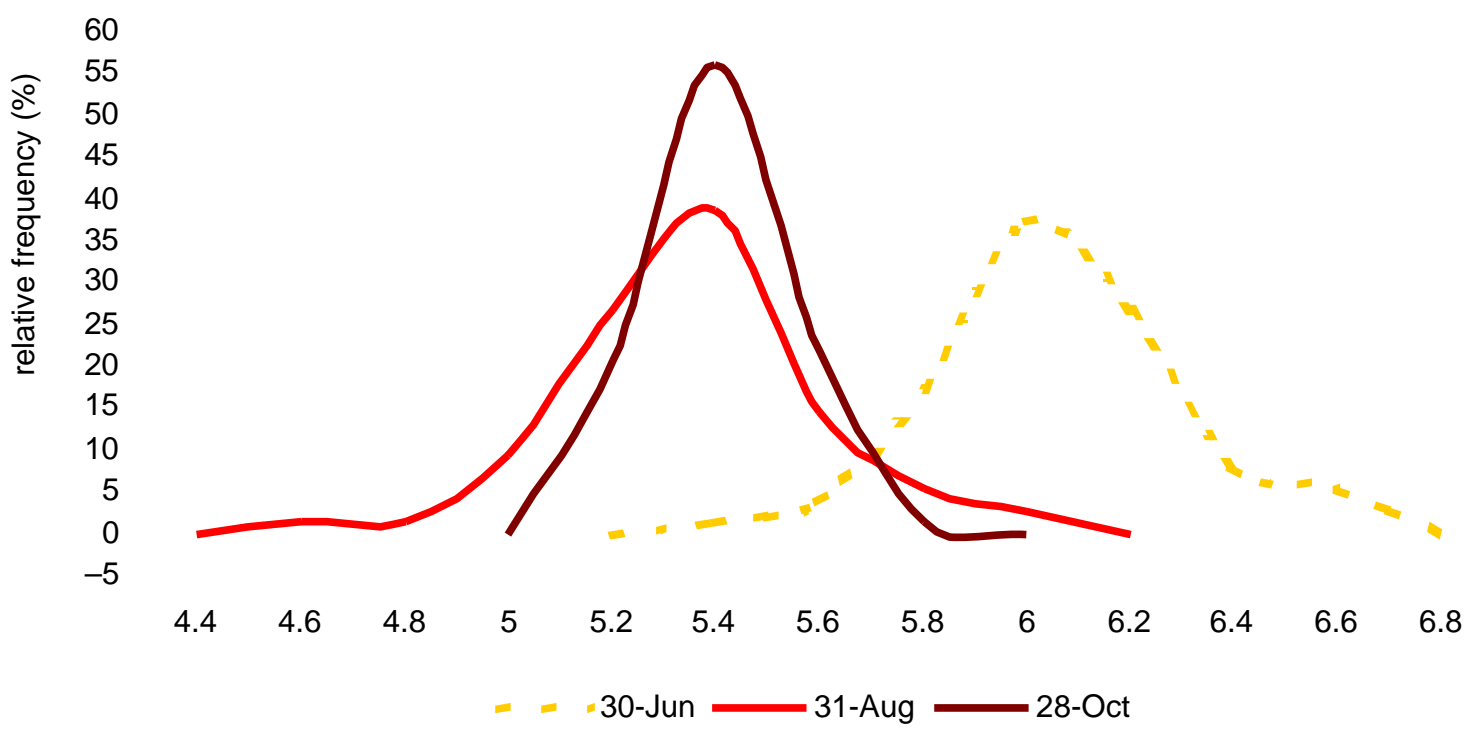


Figure 5

12-month ahead inflation expectations and targets

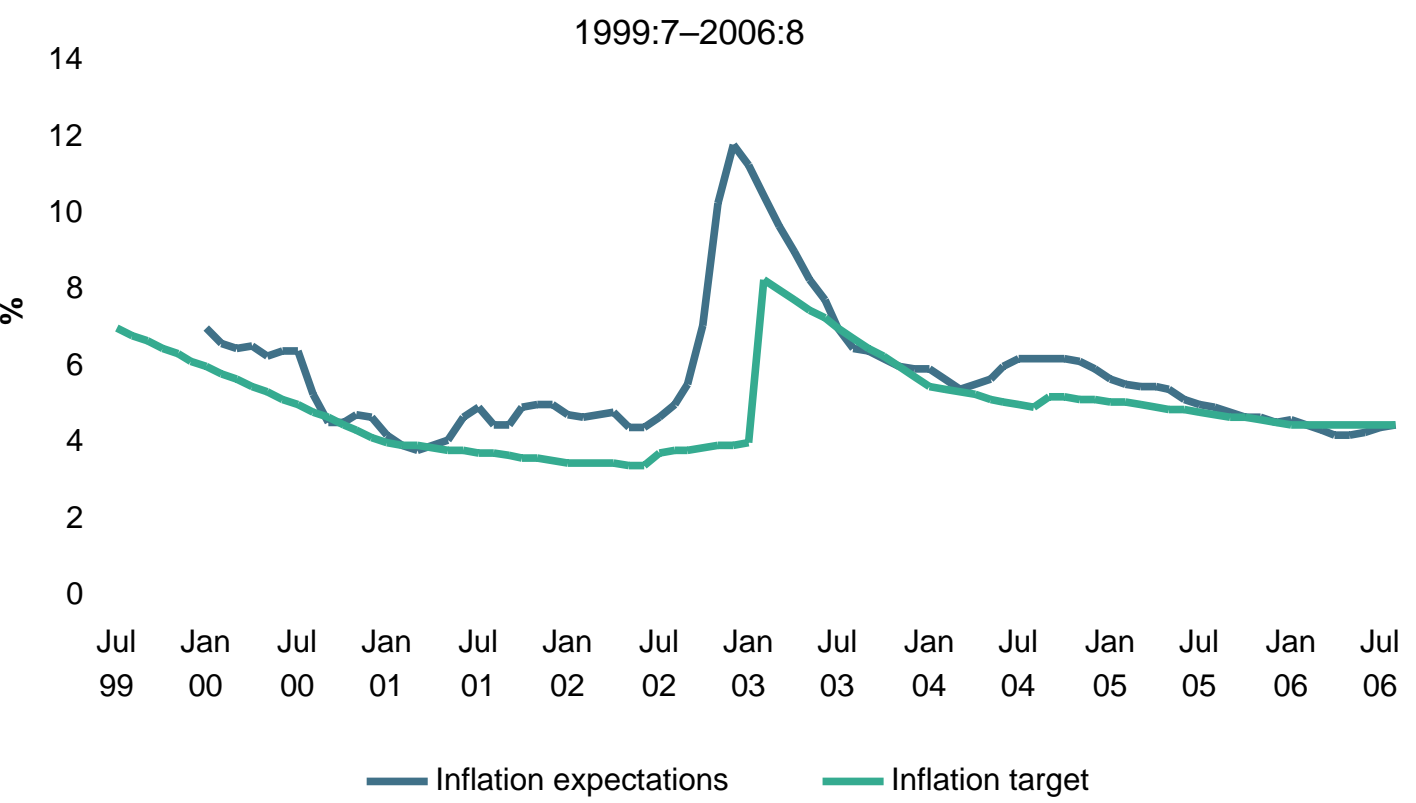

Figure 6

12-month forecast errors (2000:12-2006:8)

Actual minus forecasted inflation

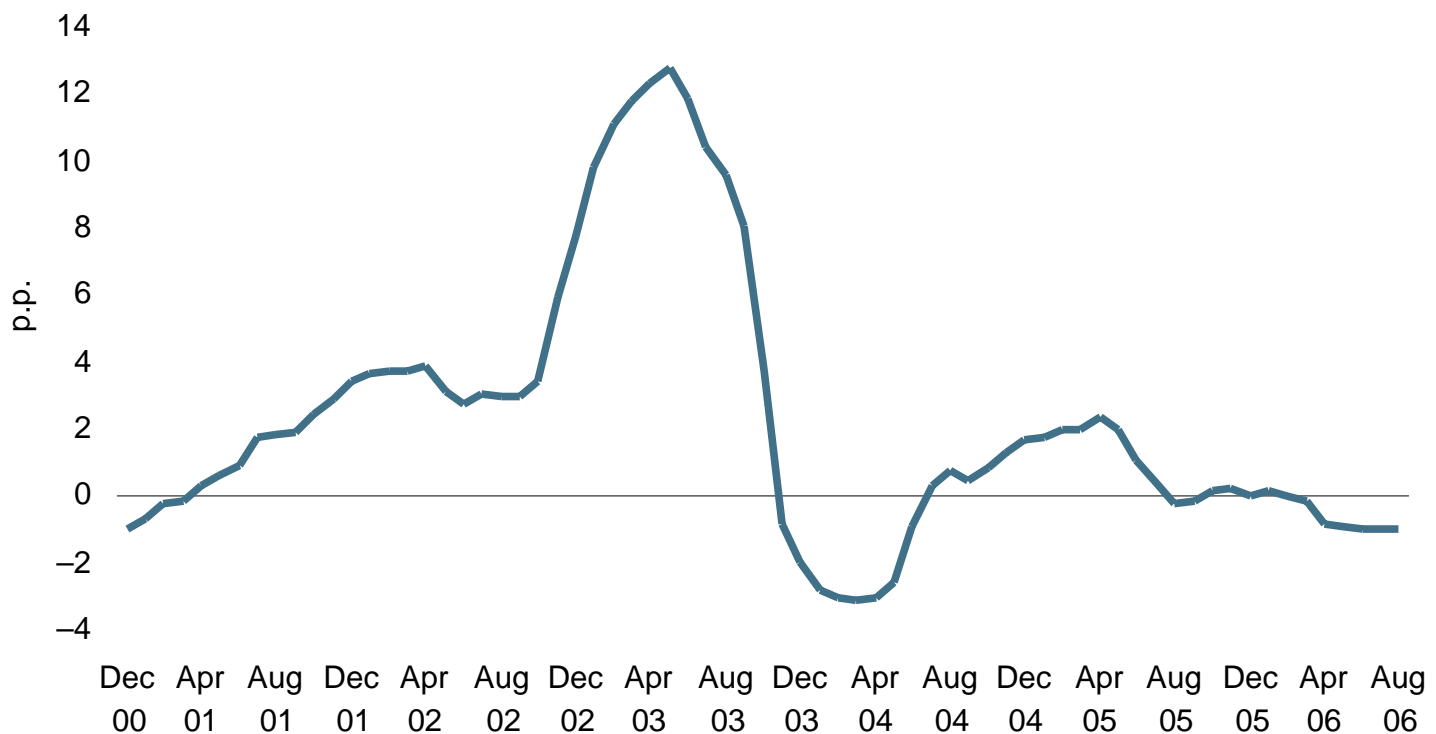


Figure 7

Dispersion of inflation expectations - coefficient of variation

2001:12-2006:8

0.35

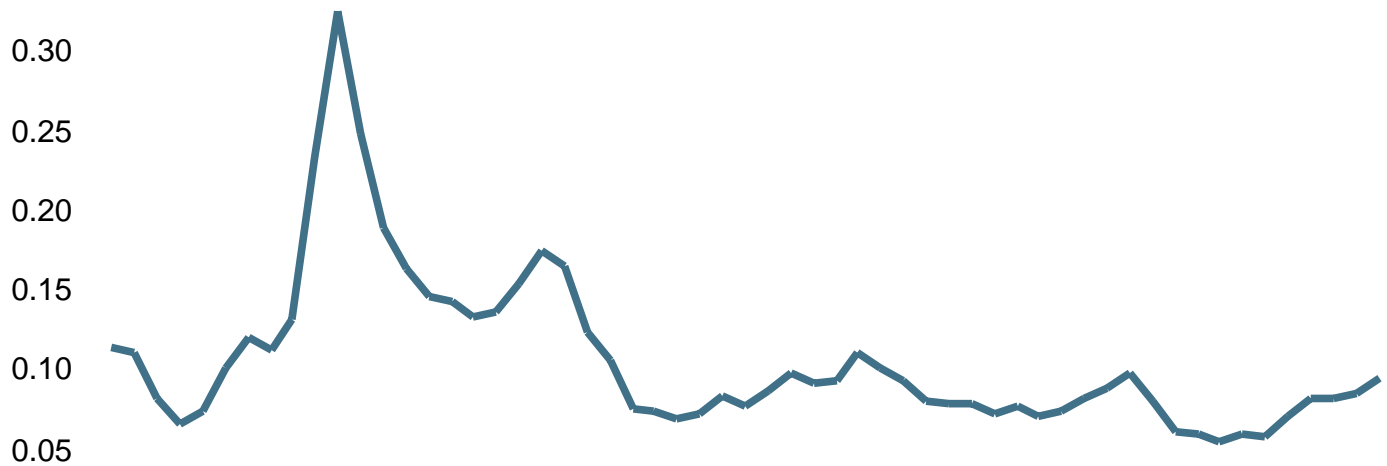

0.00

Dec Apr Aug Dec Apr Aug Dec Apr Aug Dec Apr Aug Dec Apr Aug

Figure 8

36-month rolling window regression - constant term

12

10

8

$$
6
$$

$$
4
$$

$$
2
$$

$$
0
$$$$
-2
$$$$
-4
$$$$
\begin{array}{ccccccccccccccc}
\text { Jan } & \text { Apr } & \text { Jul } & \text { Oct } & \text { Jan } & \text { Apr } & \text { Jul } & \text { Oct } & \text { Jan } & \text { Apr } & \text { Jul } & \text { Oct } & \text { Jan } & \text { Apr } & \text { Jul } \\
00 & 00 & 00 & 00 & 01 & 01 & 01 & 01 & 02 & 02 & 02 & 02 & 03 & 03 & 03
\end{array}
$$

Beggining of the sample

$$
\text { Coefficient } \quad-\quad \text { - Lower bound }-\mathrm{Cl} \quad-\quad-\text {-Upper bound }-\mathrm{Cl}
$$


Figure 9

36-month rolling window regression coefficient on the inflation target

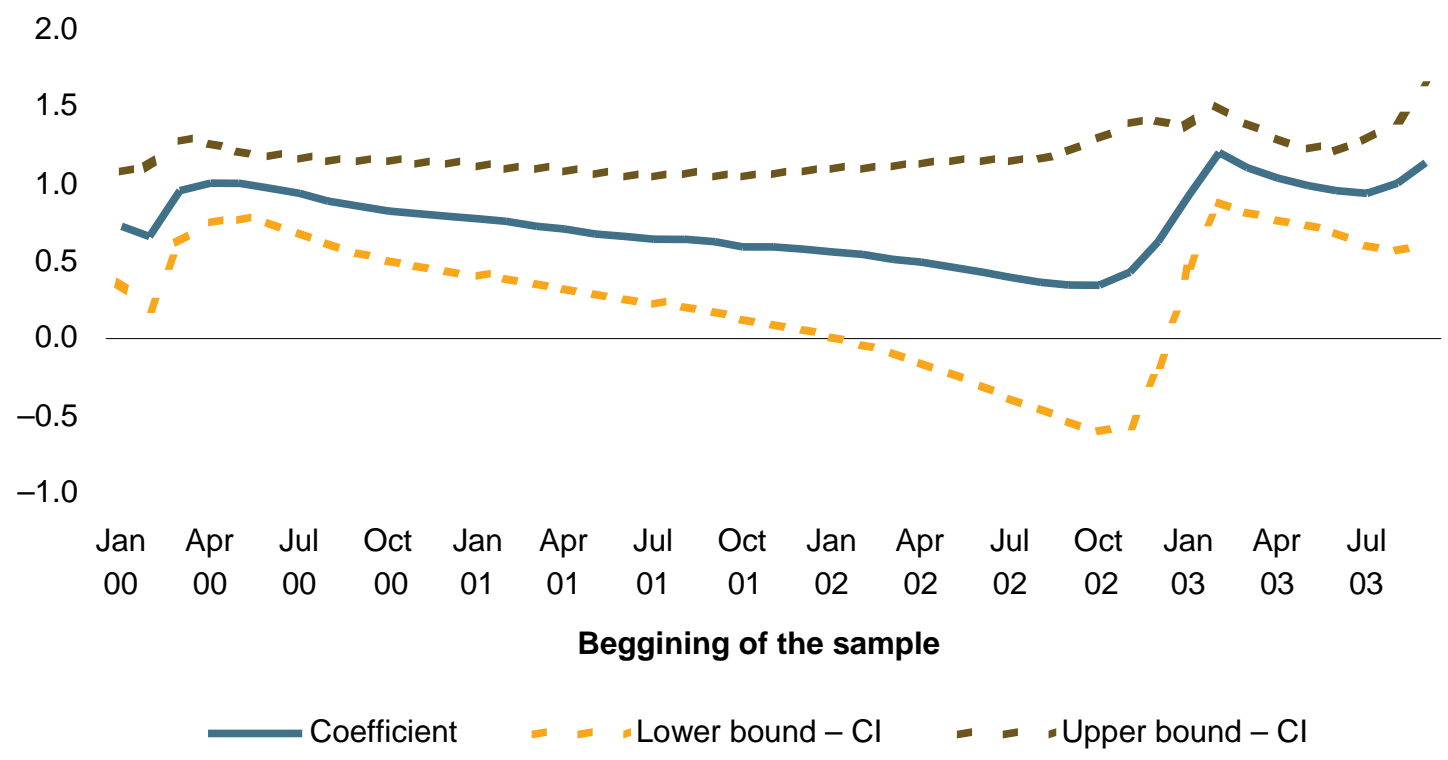

Figure 10

36-month rolling window regression - constant term

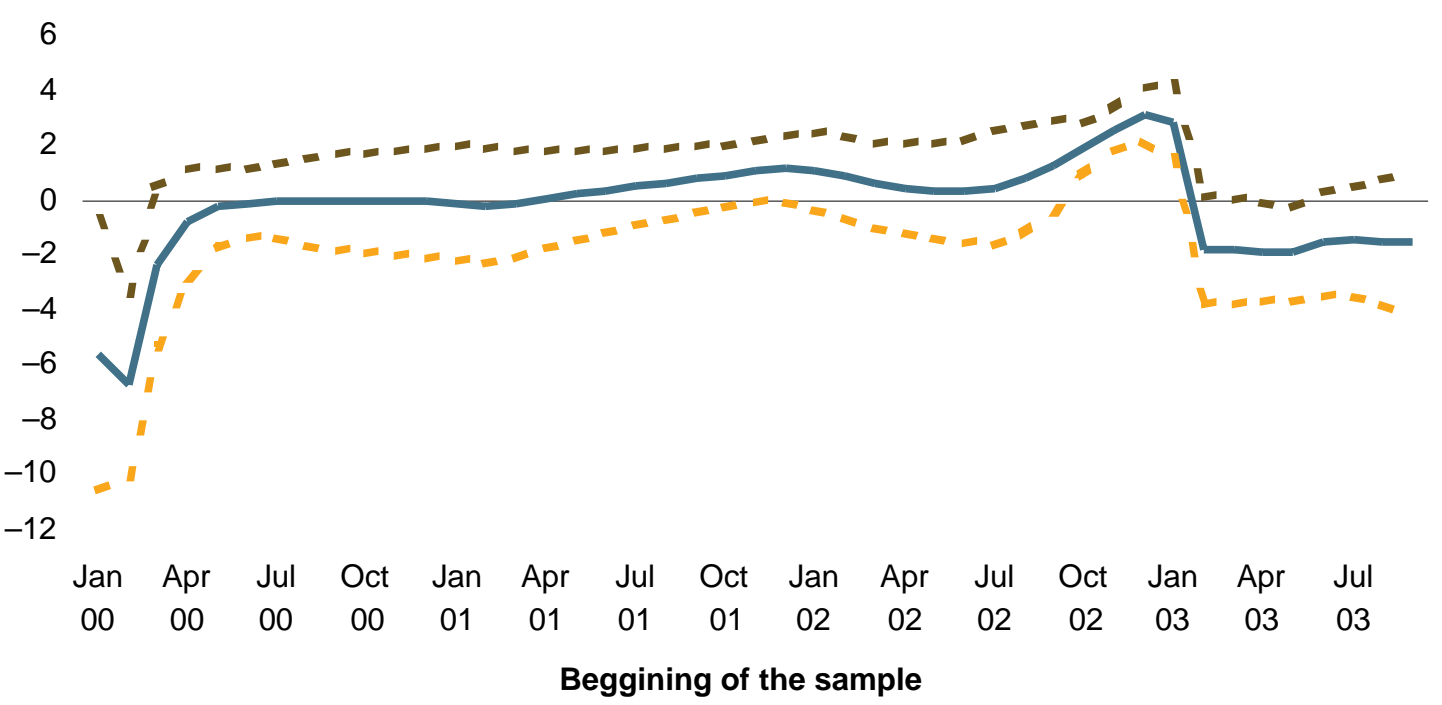

- Coefficient $\quad-\quad-$ Lower bound $-\mathrm{Cl}=-$ Upper bound $-\mathrm{Cl}$ 
Figure 11

\section{6-month rolling window regression -} coefficient on the inlation target

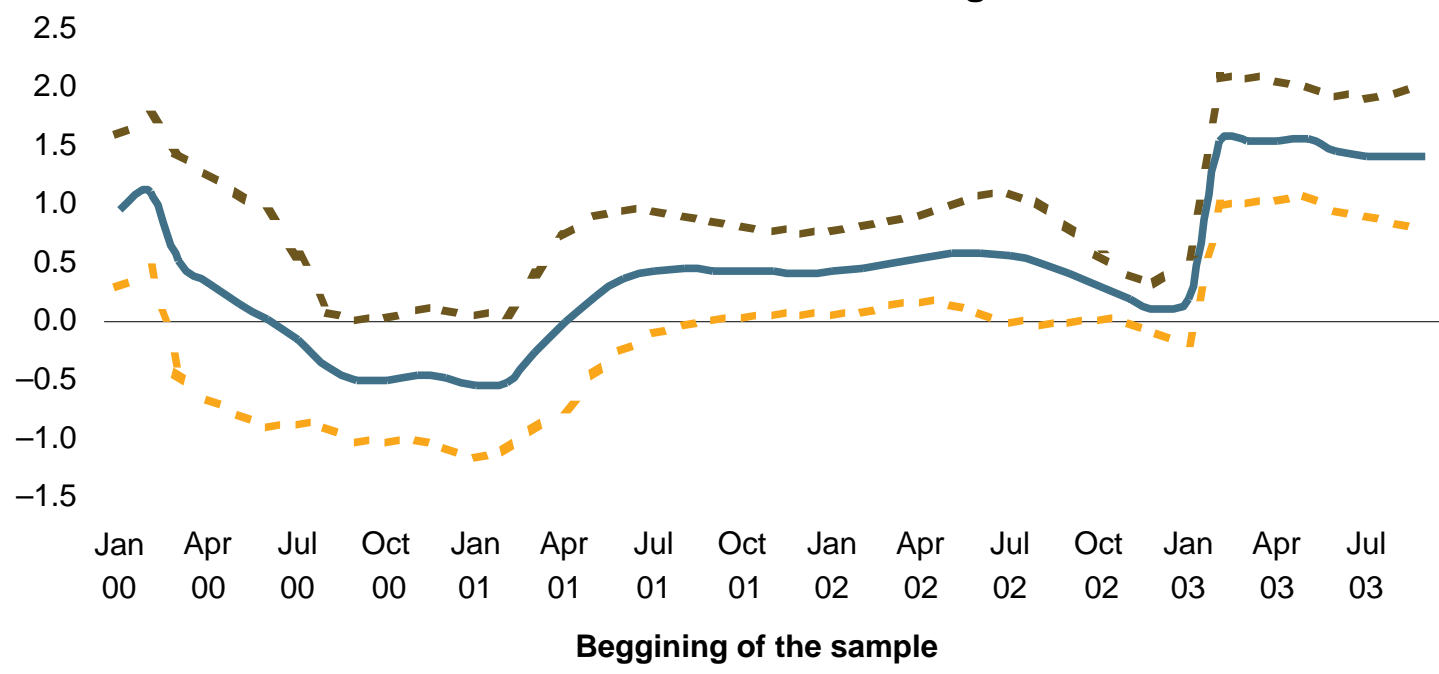

$$
\text { Coefficient }=- \text { Lower bound }-\mathrm{Cl}=- \text {.Upper bound }-\mathrm{Cl}
$$

Figure 12

\section{6-month rolling window regression - coefficient on output gap}

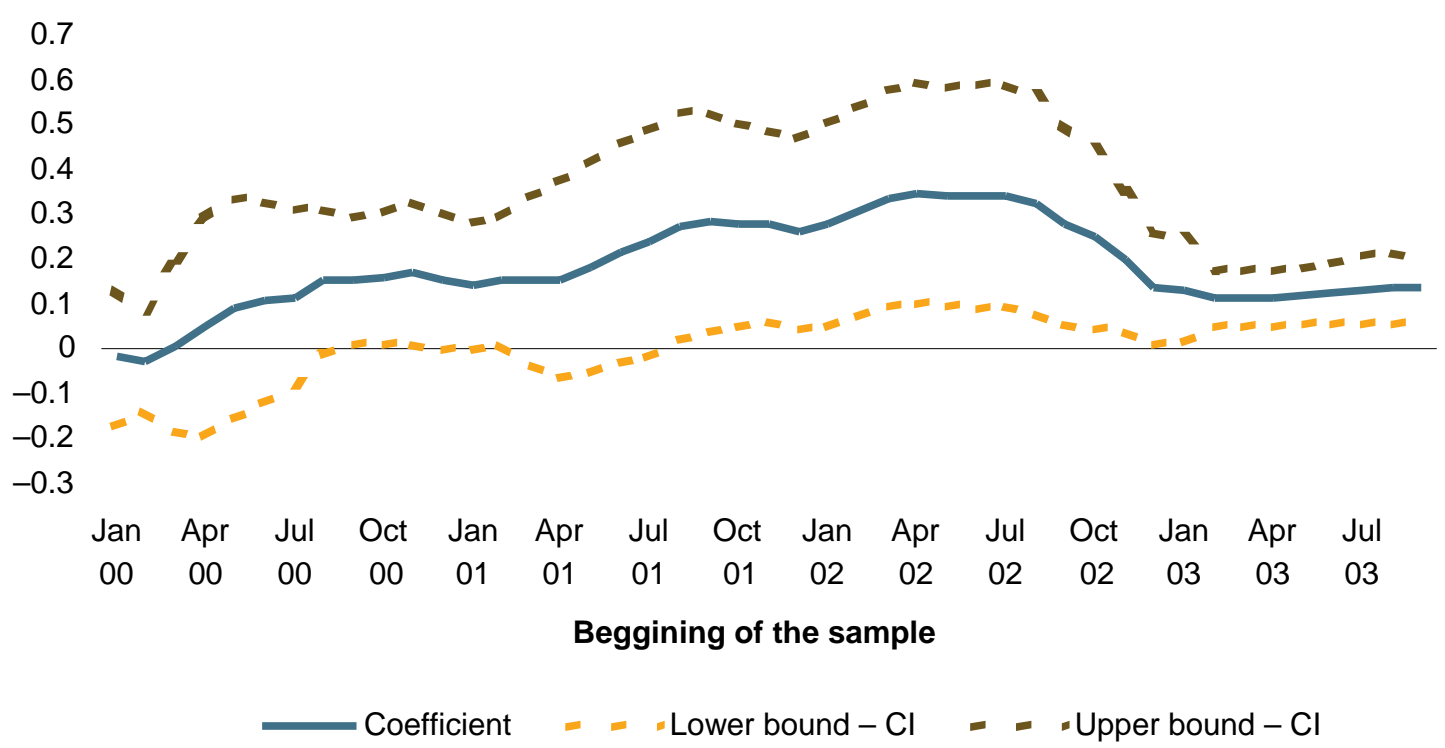


Figure 13

\section{6-month rolling window regression - coefficient on past inflation}

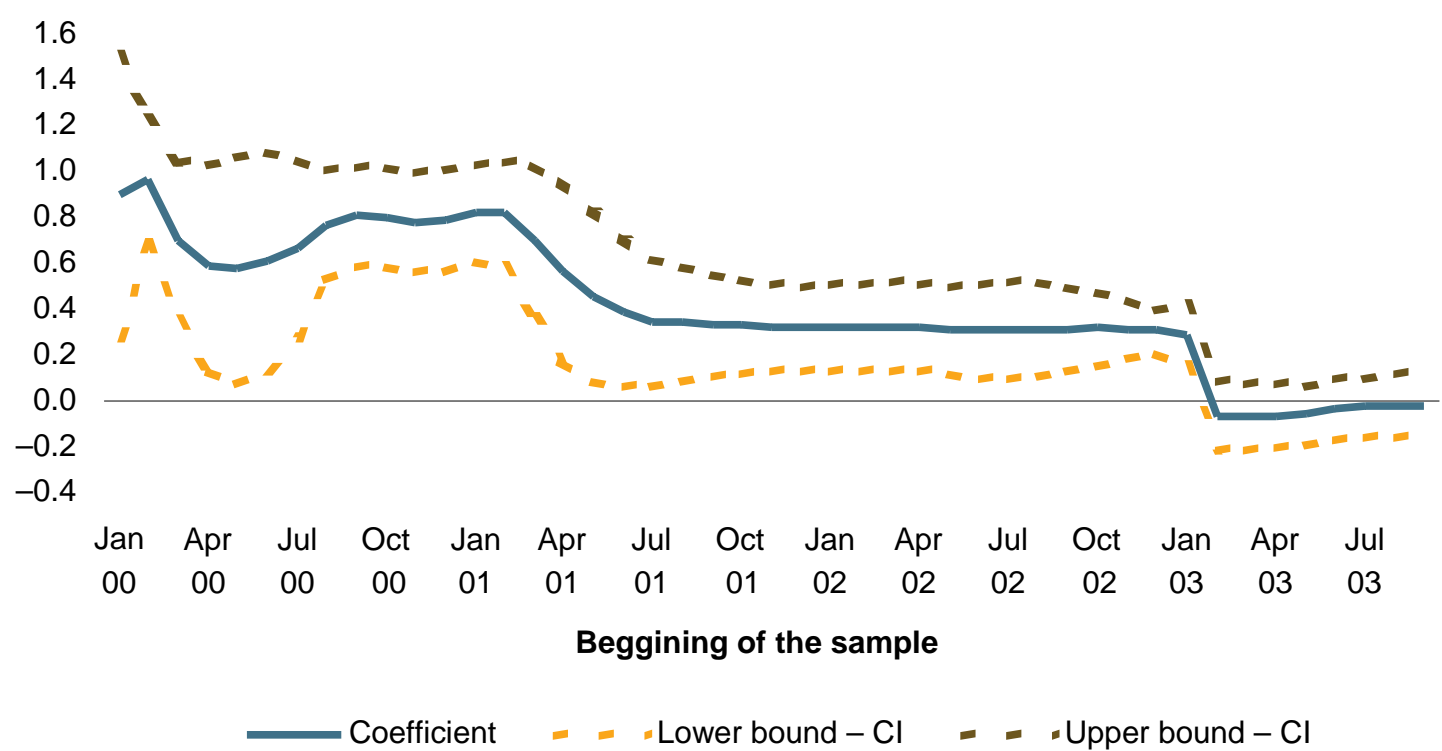

Figure 14

36-month rolling window regression coefficient on exchange rate change

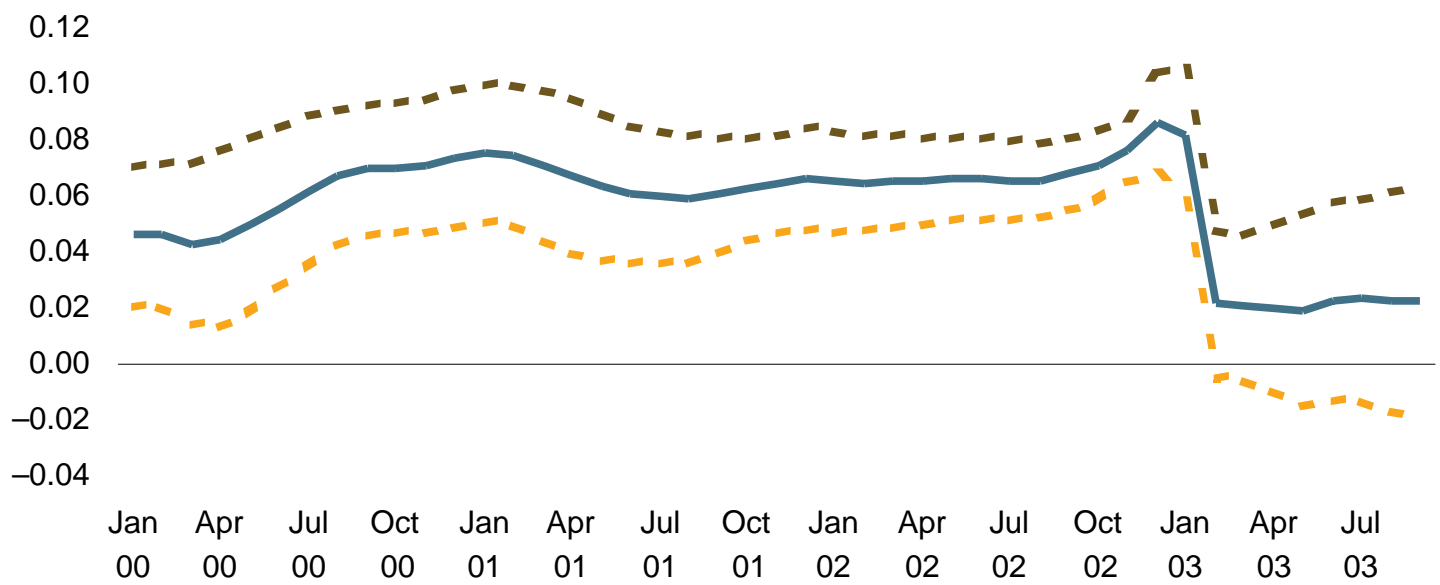

Beggining of the sample

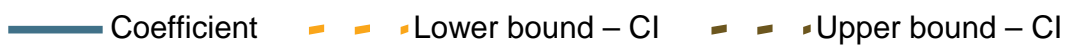




\section{References}

Alves, S A L and W D Areosa (2005): "Targets and inflation dynamics", Working Paper Series, Banco Central do Brasil, no 100, October.

Ball, L (1994): “What determines the sacrifice ratio?", in N Gregory Mankiw (ed), Monetary Policy, Chicago, University of Chicago Press, 155-82.

Banco Central do Brasil (2006): Relatório de Inflação, Sept.

Bevilaqua, A S and R Azevedo (2005): "Provision of FX hedge by the public sector: the Brazilian experience", BIS Papers, no 24, May.

Bevilaqua, A S and E Loyo (2005): "Brazil's stress test of inflation targeting", BIS Papers, no 23, May.

Blanchard, O J (2005): "Fiscal dominance and inflation targeting: lessons from Brazil", in Francesco Giavazzi, Ilan Goldfajn and Santiago Herrera (eds), Inflation targeting, debt, and the Brazilian experience, 1999 to 2003, Cambridge, MIT Press, 49-80.

Cerisola, M and R Gaston Gelos (2005): "What drives inflation expectations in Brazil? An empirical analysis", IMF Working Paper, no 109, June.

Giordani, P and P Soderlind (2003): "Inflation forecast uncertainty", European Economic Review, 47: 1037-59.

Minella, A, P S de Freitas, I Goldfajn and M K Muinhos (2003): "Inflation targeting in Brazil: constructing credibility under exchange rate volatility", Journal of International Money and Finance, 22(7):1015-1040, Dec. 